Erratum

\title{
Erratum: 29(2) p 408-412 Molecular surface directionality of the DNA-binding protein surface on the earth map
}

\author{
Wei-Po Lee ${ }^{1}$ and Wen-Shyong Tzou $^{2,3^{*}}$ \\ ${ }^{I}$ Department of Information Management, National University of Kaohsiung, Taiwan. \\ ${ }^{2}$ Institute of Bioscience and Biotechnology, National Taiwan Ocean University 2, Pei-Ning Road, \\ Keelung, Taiwan. \\ ${ }^{3}$ Department of Life Science, National Taiwan Ocean University 2, Pei-Ning Road, Keelung, Taiwan.
}

The size of Figure 2 was over-reduced. The Publisher regrets the error and publishes this figure in larger format.
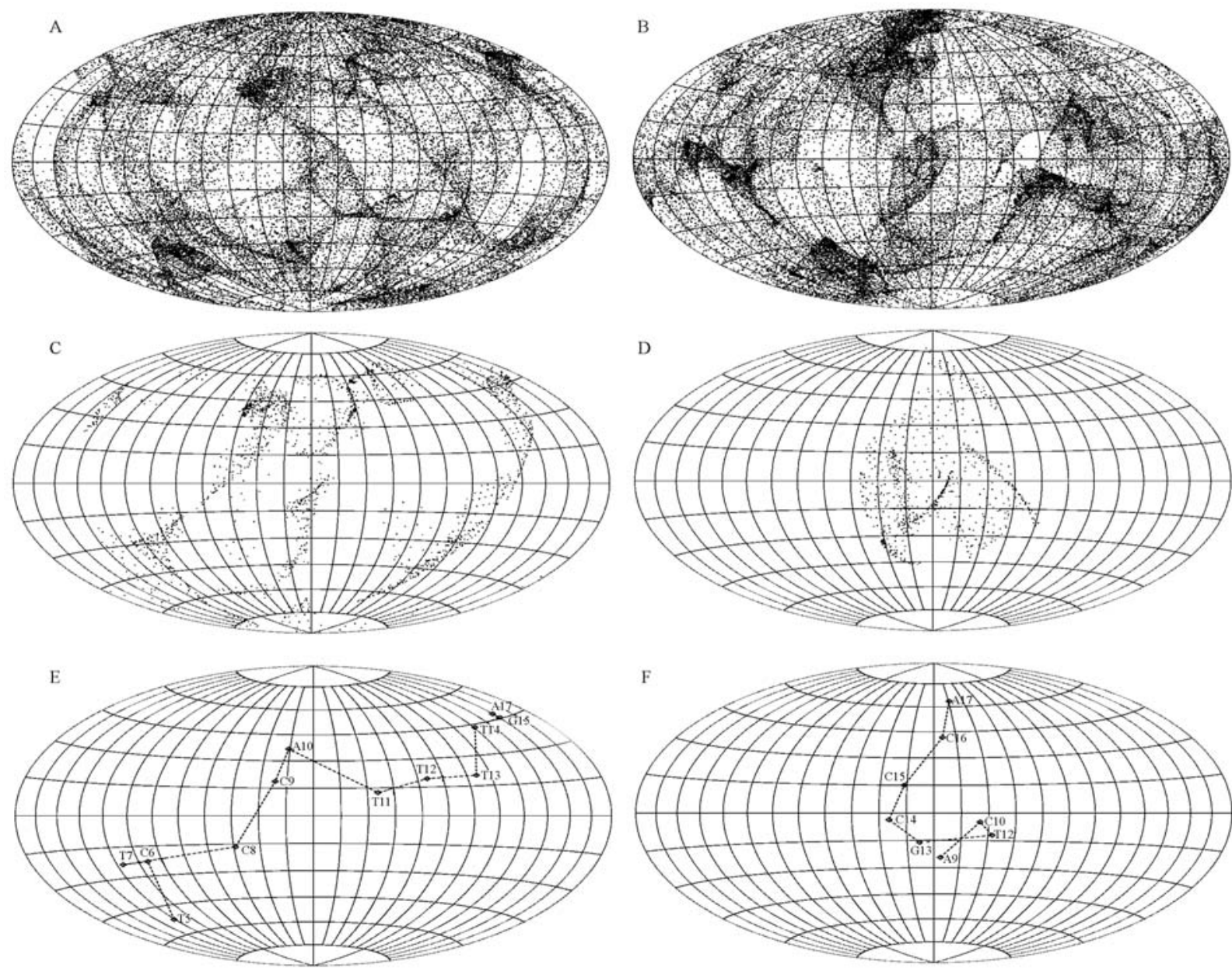

Figure 2 - Orientation distribution of the normal vectors of a protein surface shown on the earth map (A, C and E for the YY1 zinc finger-DNA complex; $\mathrm{B}, \mathrm{D}$ and $\mathrm{F}$ for the P53-DNA complex). The normal vectors for the whole protein are shown in A and B, while the normal vectors involved in the DNA contact are shown in $\mathrm{C}$ and $\mathrm{D}$. The normal vectors of the protein surface involved in DNA contact are averaged on a base-pair unit and are shown on the earth map (E, F). Each diamond-shaped symbol represents a base-pair, and they are linked with a dashed line to trace the overall orientation of the average of the normal vectors. Also shown is the nucleotide sequence of the YY1 zinc finger protein-bound DNA (nucleotide sequence T5-C6-T7-C8-C9-A10T11-T12-T13-T14-G15-A17, PDB ID: 1ubd) (E) and the P53-bound DNA (A9-C10-T12-G13-C14-C16-A17, PDB ID: 1tsr) (F). 